\title{
DETECTION OF SALMONELLA HEIDELBERG RESISTANT TO COLISTIN IN THE INTESTINAL CONTENT OF PIGS AT SLAUGHTER
}

\author{
Gabriela Orosco Werlang ${ }^{1}$, Daniel Santos Paim ${ }^{1}$, Tatiana Regina Vieira ${ }^{1}$, \\ Caroline Pissetti $^{1}$, Jalusa Deon Kich ${ }^{2}$, Marisa Cardoso ${ }^{1}$ \\ ${ }^{1}$ Departamento de Medicina Veterinária Preventiva, Faculdade de Veterinária, Universidade Federal do \\ Rio Grande do Sul, Porto Alegre, RS, Brazil \\ ${ }^{2}$ Embrapa Suínos e Aves, Concórdia, SC, Brazil
}

\begin{abstract}
Salmonella Heidelberg has increasingly been reported as cause of human salmonellosis worldwide. In Brazil, $S$. Heidelberg has been reported in poultry but it is infrequently isolated from pigs. Here, we describe the isolation of $S$. Heidelberg resistant to colistin from slaughter pigs. Five pigs and their carcasses belonging to a same slaughter batch in ten consecutive days were sampled for fragment of intestine in the ileocecal region and sponges rubbed on the carcass surface $\left(400 \mathrm{~cm}^{2}\right)$ before chilling. Salmonella detection was performed according to the ISO 6579:2002. Intestinal content was also subjected to Salmonella enumeration by a miniaturized Most Probable Number (MPN) protocol. Salmonella isolates were characterized by antimicrobial resistance by the disk diffusion test, the minimum inhibitory concentration to colistin determination and to gene $m c r-1$ investigation by PCR. Salmonella was isolated from the intestinal content of 64\% (32/50) of the pigs, in amounts that varied from 2.7 to $>1,400 \mathrm{MPN} / \mathrm{g}$. Salmonella Heidelberg was the most frequent serovar identified in the intestinal content samples $(20 / 50 ; 40 \%)$, and this serovar was present in eight of the ten pig batches sampled. At the prechill, Salmonella was isolated from $8 \%$ of carcasses, and $S$. Heidelberg was not detected. Salmonella Heidelberg strains were resistant against ampicillin $(n=9)$, tetracycline $(n=8)$, sulfonamide $(n=8)$ and gentamicin $(n=5)$. Nine multi-drug resistant strains were detected; among them four strains were positive for the gene $m c r-1$. In these strains the MIC value was $8 \mu \mathrm{g} . \mathrm{mL}^{-1}$, while in the strains without the $m c r-1$ gene it ranged from $2 \mu \mathrm{g} \cdot \mathrm{mL}^{-1}$ to $4 \mu \mathrm{g} \cdot \mathrm{mL}^{-1}$. Therefore, humans in contact with carrier pigs or their environment may be exposed to $S$. Heidelberg, including strains harboring the gene $m c r-1$.
\end{abstract}

\section{Introduction}

Salmonella enterica figures amongst the most important foodborne transmitted bacteria, and pork has been reported as a vehicle in outbreaks worldwide (EFSA, 2015). Salmonella strains isolated from pig carcasses are originated from the intestinal content of Salmonella-carrier pigs or are acquired by the contact with residual contamination of the slaughterhouse environment (BUNCIC et al., 2011). Therefore, the delivery of pig batches with a large number of animals excreting Salmonella represents a burden to the slaughtering process, in terms of bacterial load and serovar diversity. In Brazil, the high prevalence of Salmonella carrier pigs at slaughter has been reported, demonstrating that this may be a relevant factor in the Salmonella control in pork (KICH et al., 2011; SILVA et al., 2012). 
The Salmonella serovars vary in prevalence overtime and according to the region. Recently, Salmonella Heidelberg has increasingly been reported in poultry and as cause of human salmonellosis (COLLA et al., 2012; CDC, 2016; GIERALTOWSLI et al., 2016). This serovar has also been pointed out as more invasive and carrying multi-drug resistance (MDR), which represents a further concern for human and animal health (CDC, 2016; GIERALTOWSLI et al., 2016). In swine, reports of $S$. Heidelberg are still rare, being $S$. Typhimurium and $S$. Derby among the most isolated serovars worldwide (KICH et al., 2011; DENIS et al, 2013). In this study, we describe the isolation of Salmonella Heidelberg in pig batches processed in a slaughter plant from Southern Brazil and their antimicrobial resistance profile.

\section{Material and methods}

Five slaughtered pigs and their carcasses belonging to a same slaughter batch in ten consecutive days were sampled for: $i$. blood collected at bleeding; $i i$. sponges $\left(\mathrm{Nasco}^{\circledR}\right)$ rubbed on the carcass surface $\left(400 \mathrm{~cm}^{2}\right)$ after bleeding and before chilling; iii. fragment from the ileocecal region of intestine.

Serum samples were tested by the ELISA-Typhimurium test as previously described (KICH et al., 2007). The cut-off point of the test was the OD 0.169 (KICH et al., 2016). Sponges were individually suspended in $30 \mathrm{~mL}$ of buffered peptone water $1 \%$, and $5 \mathrm{~mL}$ of suspension was used for Total Aerobic Mesophilic (TAM) enumeration in Plate Count Agar (PCA) (DOWNES et al., 2011). The remaining suspension volume was used for Salmonella detection according to the ISO 6579:2002. Intestinal content $(25 \mathrm{~g})$ was suspended in $225 \mathrm{~mL}$ buffered peptone water $1 \%$ and subjected to Salmonella detection (ISO 6579:2002). It was also subjected to Salmonella enumeration by a miniaturized Most Probable Number (MPN) protocol (PAVIC et al., 2010). Salmonella isolates were serotyped at the Fundação Instituto Oswaldo Cruz (FIOCRUZ).

Antimicrobial resistance profiling was determined against twelve antimicrobials by disk-diffusion test method performed and interpreted by Clinicial and Laboratory Standards Institute, document M100 (CLSI, 2016). The following antimicrobials disks were tested: ampicillin $(10 \mu \mathrm{g})$, azithromycin $(15 \mu \mathrm{g})$, ceftiofur $(30 \mu \mathrm{g})$, cefotaxime $(30 \mu \mathrm{g})$, ceftazidime $(30 \mu \mathrm{g})$, cefotriaxone $(30 \mu \mathrm{g})$, cefoxitin $(30 \mu \mathrm{g})$, ciprofloxacin $(5 \mu \mathrm{g})$, gentamicin $(10 \mu \mathrm{g})$, meropenem $(10 \mu \mathrm{g})$, sulfonamide $(300 \mu \mathrm{g})$ and tetracycline $(30 \mu \mathrm{g})$. Furthermore, the Minimum Inhibitory Concentration (MIC) to colistin was also determined (EUCAST, 2016). Escherichia coli ATCC® 25922 was used for quality control purpose. These isolates were screened for the presence of $m c r-1$ gene by PCR with primers CLR5-F (5'-CGGTCAGTCCGTTTGTTC-3') and CLR5-R (5'CTTGGTCGGTCTGTAGGG-3') (LIU et al., 2016).

The TAM results were calculated as CFU.cm ${ }^{-2}$ and transformed into $\log 10$ for the analysis. Means of $\log 10$ CFU.cm ${ }^{-2}$ TAM were compared by the Tukey test $(p=0.05)$ of the SPSS software. 


\section{Results and discussion}

All 50 sampled pigs were positive in the ELISA-Typhimurium test demonstrating that they had been exposed to Salmonella on farm. A positive result in the ELISA-test cannot be interpreted as an active infection at slaughter; however, seropositive slaughter batches have higher chances of including pigs excreting Salmonella at slaughter (KICH et al., 2007). In this study, Salmonella was isolated from the intestinal content of $64 \%$ (32/50) of the seropositive pigs, in amounts that varied from 2.7 to $>1,400 \mathrm{MPN} / \mathrm{g}$, indicating that the burden of Salmonella-carrier pigs to the slaughter processing may be very high. Thus, hygienic measures are of utmost importance to avoid the contact of the carcass with the intestinal content and the environment contaminated with feces.

The carcasses sampled after bleeding presented TAM average of $3.28 \pm 0.53 \mathrm{log}$ cfu.cm ${ }^{-2}$ and Salmonella was isolated from 16\% (8/50) of them. At the pre-chill step, the same carcasses presented a TAM average of $1.84 \pm 0.49 \log \mathrm{cfu}_{\mathrm{cm}} \mathrm{cm}^{2}$, representing a logarithmic reduction ranging from 0.64 to $2.35 \mathrm{log} \mathrm{cfu} . \mathrm{cm}^{-2}$. Moreover, the frequency of Salmonella-positive carcasses decreases to $8 \%$ (4/50). Slaughter steps, such as singeing, can decrease the superficial microbial contamination, while others represent a hazard of adding bacteria to the surface of the carcass (BUNCIC et al., 2011). Since the monitoring of TAM reflects the change on contamination throughout the processing, the logarithmic reduction achieved demonstrated that all batches were processed in accordance with hygiene standards. As a result, the number of Salmonella-positive carcasses detected after bleeding was decrease by the half, despite the high load of Salmonella present in the intestinal content.

Salmonella Heidelberg was the most frequent serovar identified in the intestinal content samples $(20 / 50 ; 40 \%)$, and this serovar was present in eight of the ten batches. In spite of that, $S$. Heidelberg was detected neither in carcasses after bleeding nor at the prechilling, which indicate that the slaughter process might have been able to control the contamination by this serovar. Salmonella Heidelberg has infrequently been reported in pigs and pork (KICH et al., 2011; EFSA, 2015). On the other hand, this serovar has been increasingly prevalent in poultry and humans (COLLA et al., 2012; FOLSTER et al, 2012; GIERALTOWSKI et al., 2016; PALMEIRA et al., 2016). Noteworthy is that $S$. Heidelberg has been associated with invasive human infections and high mortality rates (CRUMP et al., 2011). Moreover, a $S$. Heidelberg outbreak in humans in close contact with cattle was reported (CDC, 2016), demonstrating that this is another possible transmission route to humans. Antimicrobial resistance in $S$. Heidelberg is of particular concern, since MDR strains have been implicated in human outbreaks (GIERALTOWSKI et al., 2016). In this sense, the 20 Salmonella strains tested were fully susceptible to azithromycin, cephalosporin (ceftiofur, cefotaxime, ceftazidime, cefotriaxone, and cefoxitin), ciprofloxacin and meropenem, antimicrobials considered as highly critical to human treatment (WHO, 2012). Resistance was detected against ampicillin $(n=9)$, tetracycline $(n=8)$, sulphonamide $(n=8)$, gentamicin $(n=5)$. A total of nine MDR strains (resistant to $\geq 3$ antimicrobial classes) were identified. Four MDR strains presenting a profile including all the four aforementioned antimicrobials were also positive for the gene $m c r-1$, demonstrating that they were resistant to colistin. In all resistant strains the MIC value was $8 \mu \mathrm{g} \cdot \mathrm{mL}^{-1}$, while in the susceptible strains it ranged from $2 \mu \mathrm{g} . \mathrm{mL}^{-1}$ to $4 \mu \mathrm{g} . \mathrm{mL}^{-1}$. The presence of the gene $m c r-1$ in Salmonella is a concern, since colistin is considered the last resource for treatment of MDR bacteria in humans and the gene is usually located in transferable genetic elements (LIU et al., 2016). 


\section{Conclusion}

Although not detected in carcasses in this study, the identification of $S$. Heidelberg in the intestinal content demonstrated that this serovar is circulating in pigs and might eventually also be found in pork. Therefore, humans in contact with carrier pigs or their environment may be exposed to $S$. Heidelberg, including to strains harboring the gene $m c r-1$.

\section{References}

BUNCIC, S.; SOFOS, J. Interventions to control Salmonella contamination during poultry, cattle and pig slaughter. Food Research International, v. 45, p. 641-655, 2012.

CDC, Centers for Disease Control and Prevention. Multistate outbreak of multidrug-resistant Salmonella Heidelberg infections linked to contact with dairy bull calves; 2016.

CLSI, Clinical and Laboratory Standards Institute. M100. Performance Standards for Antimicrobial Susceptibility Testing. Wayne: 2016. 26rd ed.

COLLA, F. L. et al. Isolamento de Salmonella Heidelberg em diferentes pontos da tecnologia de abate de frangos de corte. Arquivos do Instituto Biológico, v. 79, n.4, p. 603-606, 2012.

CRUMP, J.A. et al. Antimicrobial resistance among invasive nontyphoidal Salmonella enterica isolates in the United States: National Antimicrobial Resistance Monitoring System, 1996 to 2007. Antimicrobial Agents and Chemotherapy, v. 55, n. 3, p.1148-1154, 2011.

DENIS, M. et al. Distribution of serotypes and genotypes of Salmonella enterica species in French pig production. Veterinary Record, v.173, 2013.

DOWNES, F.P.; ITO, K. editor. Compendium of Methods for the Microbiological Examination of Foods, American Public: Health Association; 2011.

EFSA, European Food Safety Authority. The European Union summary report on trends and sources of zoonoses agents and food-borne outbreaks in 2013. EFSA Journal. 2015;13(1):2991.

EUCAST, European Committee on Antimicrobial Susceptibility Testing. Breakpoint tables for interpretation of MICs and zone diameters. Version 6.0, 2016.

FOLSTER, J.P. et al. Characterization of multidrug-resistant Salmonella enterica serovar Heidelberg from a ground turkey-associated outbreak in the United States in 2011. Antimicrobial Agents and Chemotherapy, v. 56, n. 6, p. 3465-3466, 2012.

GIERALTOWSKI, L. et al. National outbreak of multidrug resistant Salmonella Heidelberg infections linked to a single poultry company. PloS One, v. 11, n. 9, p. e0162369, 2016.

ISO 6579:2002. Microbiology of food and animal feeding stuffs - Horizontal method for the detection of Salmonella spp. 2002.

KICH, J.D. et al. Development and application of an enzyme-linked immunosorbent assay to detect antibodies against prevalent Salmonella serovars in swine in southern Brazil. Journal of veterinary diagnostic investigation, v. 19, n. 5, p. 510-517, 2007.

KICH, J.D. et al. Prevalence, distribution, and molecular characterization of Salmonella recovered from swine finishing herds and a slaughter facility in Santa Catarina, Brazil. International Journal of Food Microbiology, v. 151, n. 3, p. 307-313, 2011.

KICH, J.D. et al. Assessment of different cut-off values of the ELISA-Typhimurium for the discrimination of swine herds with Salmonella isolation. Semina. Ciências Agrárias, v. 37, p. 3107, 2016. 
LIU, Y.-Y. et al. Emergence of plasmid-mediated colistin resistance mechanism MCR-1 in animals and human beings in China: a microbiological and molecular biological study. The Lancet. Infectious Diseases, v. 16, n. 2, p. 161-168, 2016.

PALMEIRA, A. et al. Serovars and antimicrobial resistance of Salmonella spp. isolated from turkey and broiler carcasses in southern brazil between 2004 and 2006. Revista do Instituto de Medicina Tropical de São Paulo, v. 58, n. 19, 2016.

PAVIC, A. et al. A validated miniaturized MPN method, based on ISO 6579:2002, for the enumeration of Salmonella from poultry matrices. Journal of Applied Microbiology, v. 109, p. 25-34, 2010.

SILVA, L.E. et al. Longitudinal dissemination of Salmonella enterica clonal groups through the slaughter process of Salmonella-positive pig batches. Journal of Food Protection, v. 75, p. 1580-1588, 2012.

WHO, World Health Organization. Critically important antimicrobials for human medicine. $3^{\text {rd }}$ revision $2011 ; 2012$. 